\title{
A new species of Bicurta Sheng et al. from China (Hymenoptera, Ichneumonidae, Collyriinae), a parasitoid of Stenocephus fraxini Wei (Hymenoptera, Cephidae)
}

\author{
Jing-Xian Liu', Jia-He Yan², Gavin R. Broad ${ }^{3}$ \\ I Department of Entomology, South China Agricultural University, Guangzhou 510642, China 2 Shanghe \\ Forest Pest Management and Quarantine Station of Shandong Province, Shanghe, 251600, China 3 De- \\ partment of Life Sciences, the Natural History Museum, Cromwell Road, London SW75BD, UK \\ Corresponding author: Jing-Xian Liu (liujingxian@scau.edu.cn); Gavin R. Broad (g.broad@nhm.ac.uk) \\ Academic editor:J. Fernandez-Triana | Received 30 August 2019 | Accepted 30 October 2019 | Published 30 December 2019 \\ http://zoobank.org/8B591C56-E2DC-4F55-BA45-2B2111F1A13C \\ Citation: Liu J-X, Yan J-H, Broad GR (2019) A new species of Bicurta Sheng et al. from China (Hymenoptera, \\ Ichneumonidae, Collyriinae), a parasitoid of Stenocephus fraxini Wei (Hymenoptera, Cephidae). Journal of Hymenoptera \\ Research 74: 93-104. https://doi.org/10.3897/jhr.74.39570
}

\begin{abstract}
A new species of the genus Bicurta Sheng, Broad \& Sun, 2012, is described and illustrated, B. hejunhuai sp. nov., from North and Northeast China. The new species was reared from the stem-sawfly Stenocephus fraxini Wei (Hymenoptera, Cephidae), which is the first host record for the genus Bicurta.
\end{abstract}

\section{Keywords}

Parasitoid, new species, biological control, China

\section{Introduction}

Collyriinae is small subfamily of Ichneumonidae, including only three genera (Aubertiella Kuslitzky \& Kasparyan, Bicurta Sheng et al., and Collyria Schiødte) with 11 described species, all distributed in the Palaearctic region (Gürbüz and Kolarov 2006; Wahl et al. 2007; Kuslitzky and Kasparyan 2011; Sheng et al. 2012; Yu et al. 2016; Broad et 
al. 2018), although with Bicurta sinica Sheng et al. found in both the Palaearctic and Oriental regions (Sheng et al. 2012, 2013; Shang et al. 2016). The systematics of this subfamily, based on morphological characters, were discussed by Sheng et al. (2012).

The genus Bicurta is monotypic, with only the type species B. sinica described from Jiangxi Province of China (Sheng et al. 2012). Shang et al. (2016) reported a male specimen of B. sinica from Liaoning Province in Northeast China. The biology of the genus Bicurta was not known until this study.

During a survey of pests of Fraxinus chinensis Roxb. and F. mandshurica Rupr. (Lamiales, Oleaceae) in Northeast China (Yan et al. 2018, 2019), the second author reared about 40 specimens of Bicurta from larvae of the stem-sawfly Stenocephus fraxini Wei, 2015 (Hymenoptera, Cephidae) which is a very common pest of urban greening trees, Fraxinus spp. (Lamiales, Oleaceae), in Northeast China (Fig. 26) (Yan et al. 2018), mainly from the downtown of Shenyang City, Liaoning Province.

The aim of this study is to describe a new species of Bicurta parasitizing S. fraxini Wei.

\section{Materials and methods}

Parasitoids were reared in the laboratory from larvae of Stenocephus fraxini collected in branches of Fraxinus spp. from North and Northeast China (Inner Mongolia, Liaoning and Heilongiiang), mainly from the downtown of Shenyang City. Photographs were taken using a KEYENCE VHX-5000 Digital Microscope imaging system and processed with Photoshop CS software.

Morphological terms follow Broad et al. (2018). Abbreviations used in the text are as follows: $\mathrm{POL}=$ the shortest distance between posterior ocelli; $\mathrm{OD}=$ diameter of a posterior ocellus; $\mathrm{OOL}=$ the shortest distance between a posterior ocellus and a compound eye. Type material of the new species is deposited in South China Agricultural University, Guangzhou, Guangdong (SCAU).

\section{Taxonomy}

\section{Genus Bicurta Sheng, Broad \& Sun, 2012}

Type species. Bicurta sinica Sheng et al., 2012.

Diagnosis. This genus is distinguished from Collyria by the epicnemial carina indistinct because of sculpture on the mesopleuron; ovipositor straight and smooth (Fig. 12), lacking teeth on the ventral valve; and the fore and mid tarsal claws each having an acutely lobed tooth (Figs 10, 24) (Sheng et al. 2012), while in the other two other collyriine genera, Aubertiella and Collyria, fore and mid tarsal claws with a median tooth, rather than a lobe.

Biology. Adults of the new species emerged from larvae of Stenocephus fraxini Wei (Hymenoptera, Cephidae) from March to May 2019 in Northern China. This is the 
first report of a host of Bicurta, which is consistent with the known biology of Collyria, as parasitoids of stem-sawflies (Hymenoptera, Cephidae).

Based on the field work survey during 2018 to 2019, the parasitism rate of this species on $S$. fraxini was $59.3 \%$ on average in the downtown of Shenyang city (J.H. Yan, unpublished data).

\section{Bicurta hejunhuai Liu, Yan \& Broad, sp. nov.} http://zoobank.org/FCDA6C05-C21E-4FE1-AD15-B5B0B79C55B7 Figs 1-26

Material examined. Holotype female, CHInA: Liaoning Province, Shenyang City, 2230 March 2019, leg. Jia-He Yan, reared from larva of Stenocephus fraxini Wei (SCAU). Paratypes $2 \circ+q$ and $21 \widehat{\partial} \widehat{\partial}$, same data as holotype (SCAU); 1 female, Inner Mongolia Autonomous region of China, Huhehot, Wulanfu Park, 24 March 2019, leg. Jia-He Yan (SCAU); 2 우, Heilongjiang Province, Harbin, Botany Garden of Harbin, reared from Fraxinus mandshurica Rupr. (Lamiales, Oleaceae), 7 May 2019, leg. Jia-He Yan (SCAU); $40+q$ and $9 \hat{\jmath} \hat{\jmath}$, Liaoning Province, Shenyang, collected from Fraxinus chinensis Roxb. and F. pennsylvanica Marsh., 25 April 2019, leg. Jia-He Yan (SCAU).

Description. Holotype, female (Fig. 1). Body length $10.0 \mathrm{~mm}$, fore wing length $6.2 \mathrm{~mm}$, antenna length $3.8 \mathrm{~mm}$, ovipositor length $1.6 \mathrm{~mm}$.

Head. Face flat (Fig. 2), 1.2× as wide as high, centrally with sparse punctures, distance between punctures of central area 1.0 to $5.0 \times$ diameter of punctures, punctures close below antennal sockets and near inner orbits; face next to inner orbit with fine granular texture. Clypeus (Fig. 1) $2.2 \times$ as wide as high, finely and sparsely punctate, apical margin with an obtuse median tubercle, impunctate. Mandible weakly narrowed to apex, middle width of mandible $0.57 \times$ as wide as basal width of mandible, with lower tooth slightly longer than upper tooth. Labrum not exposed. Malar space short (Fig. 4), finely wrinkled and with fine leathery texture in between, $0.33 \times$ as long as basal mandibular width. Gena (Fig. 3) evenly convergent posteriorly, finely punctulate and pubescent, $0.63 \times$ as long as eye in dorsal view. Vertex (Fig. 3) with posterior portion finely punctulate, between lateral ocellus and eye with fine leathery texture. $\mathrm{POL}=1.0$, $\mathrm{OD}=1.25, \mathrm{OOL}=1.0$. Interocellar area flat with a short longitudinal groove. Frons finely punctate above antennal sockets, centrally with a weak longitudinal carina extending between antennal sockets to median ocellus, frons slightly rugose along carina sides. Antenna (Fig. 8) with 19 flagellomeres, ratio of length of basal five flagellomeres as follows: $1.42: 1.25: 1.17: 1.08: 1.0$, first flagellomere $2.83 \times$ as long as its apical width, apical flagellomere $2.4 \times$ as long as its basal width, slightly shorter than fourth flagellomere $(12: 14)$. Occipital carina sharp and strong. Distance from hypostomal carina to mandible $1.25 \times$ longer than basal mandibular width.

Mesosoma. Propleuron finely and densely punctate, pubescent. Pronotum (Fig. 4) strongly sculptured, central depressed portion with anteriorly arched longitudinal wrinkles, dorsal half irregularly strongly rugose, with epomia indistinctly 


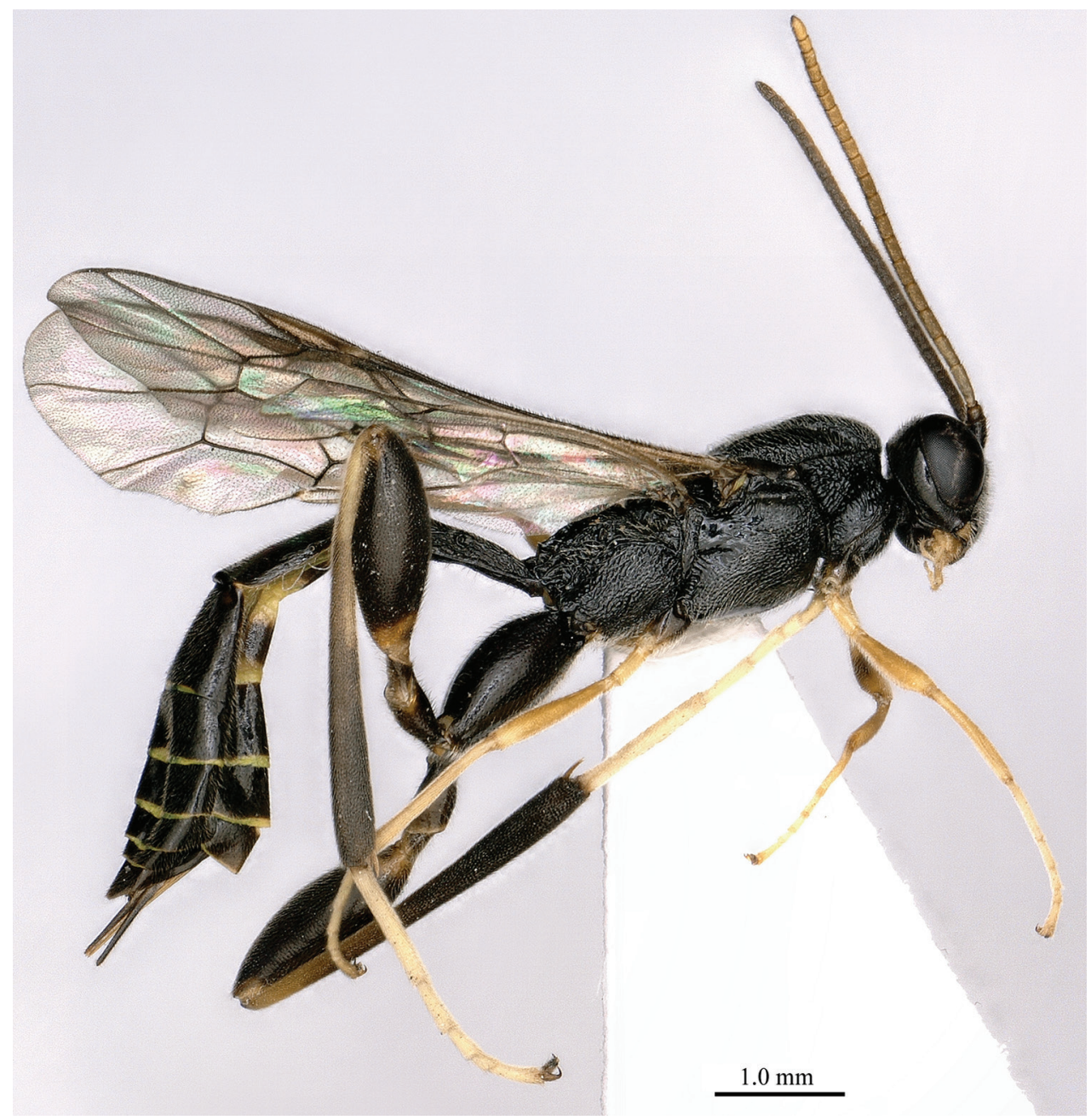

Figure I. Bicurta hejunhuai sp. nov. (female holotype), habitus, lateral view.

differentiated from these rugae. Mesoscutum (Fig. 5) with median lobe slightly convex in lateral view, median lobe with irregularly distributed fine punctures which are sparser centrally; punctures on lateral lobe sparser than those on median lobe; notaulus deep notaulus deep and crenulate, mesoscutum centrally with a short longitudinal groove behind median lobe and between meeting point of notauli; posterior median portion of mesoscutum polished, with sparse punctures. Scutellum (Fig. 5) evenly and slightly convex, sparsely punctate, distance between punctures 1.0 to 2.0× diameter of puncture. Metanotum rugose punctate. Epicnemial carina (Fig. 7) distinct ventrally and obscure dorsally, not prominent in front of median longitudinal suture. Mesopleuron (Figs 7, 13,23) largely densely punctate reticulate and pubescent; dorsal anterior portion in front of subtegular ridge with short irregular longitudinal wrinkles; below subtegular ridge and in front of speculum slightly ru- 

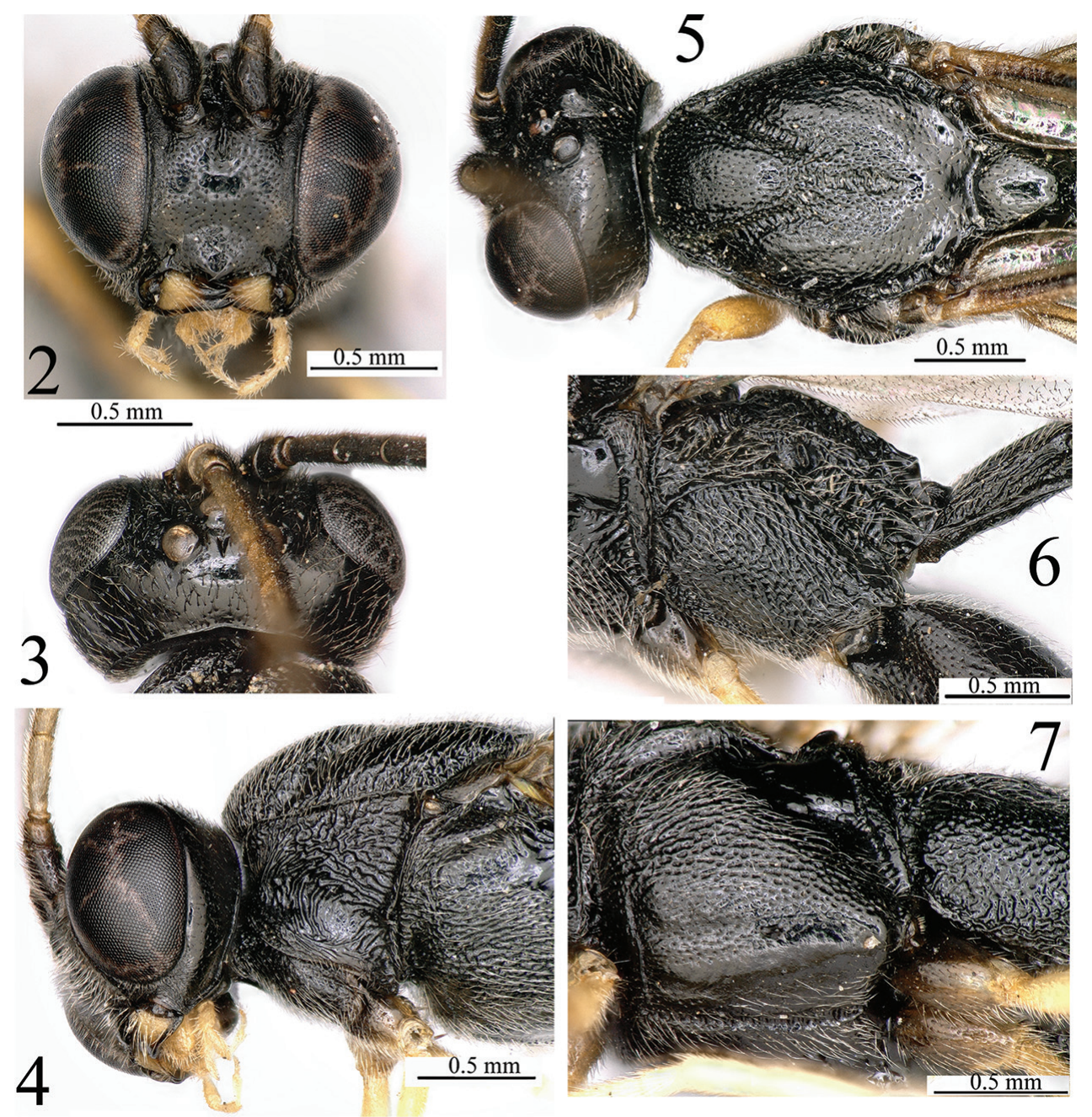

Figure 2-7. Bicurta hejunhuai sp. nov. (female holotype) $\mathbf{2}$ face, frontal view $\mathbf{3}$ head, dorsal view $\mathbf{4}$ head and frontal half of mesosoma, lateral view $\mathbf{5}$ head and mesoscutum, dorsal view $\mathbf{6}$ metapleuron, propodeum and base of first tergite, lateral view $\mathbf{7}$ mesopleuron and mesosternum, lateroventral view.

gulose; ventroposterior portion below episternal scrobe with short wrinkles, more or lese shiny. Speculum (Fig. 13) relatively large, as long as (or $0.6 \times$ as wide as) length of tegula, polished and glabrous. Mesopleural furrow distinctly foveolate. Mesosternum (Fig. 7) along medial sternal groove more or less polished, with a few sparse punctures laterally and centrally. Median longitudinal suture of mesosternum distinct, inner side with short transverse carinae. Metapleuron (Fig. 6) scabrous, evenly convex, dorsal portion strongly rugose, central portion punctate reticulate, ventral portion irregularly rugulose. Submetapleural carina present on anterior 0.4 of metapleuron, weakly convex, posterior 0.6 of submetapleural carina replaced by wrinkles. Metasternum $0.8 \times$ as long as mesosternum, with irregular transverse wrinkles. Pro- 


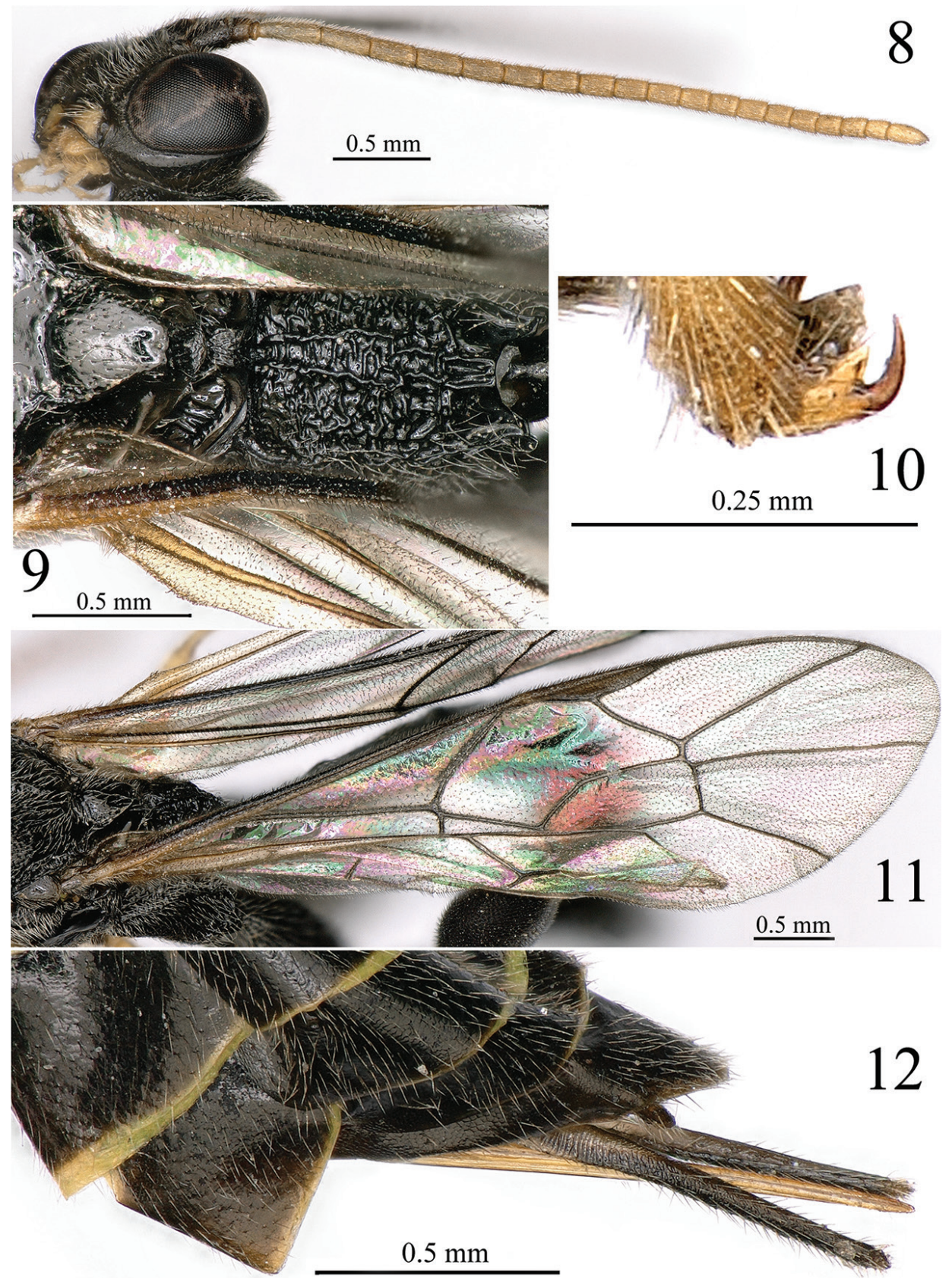

Figures 8-12. Bicurta hejunhuai sp. nov. (female holotype) 8 head and antenna, lateral view 9 scutellum and propodeum, dorsal view $\mathbf{I} \mathbf{0}$ mid claw, lateral view $\mathbf{I} \mathbf{I}$ fore wing $\mathbf{I} \mathbf{2}$ apex of metasoma and ovipositor, lateral view.

podeum elongate (Figs 6, 9, 14), strongly rugose; median longitudinal carinae strong and reaching to posterior end of propodeum, anteriorly convergent, with transverse wrinkles in between; dorsal area with irregular wrinkles; pleural area with transverse 

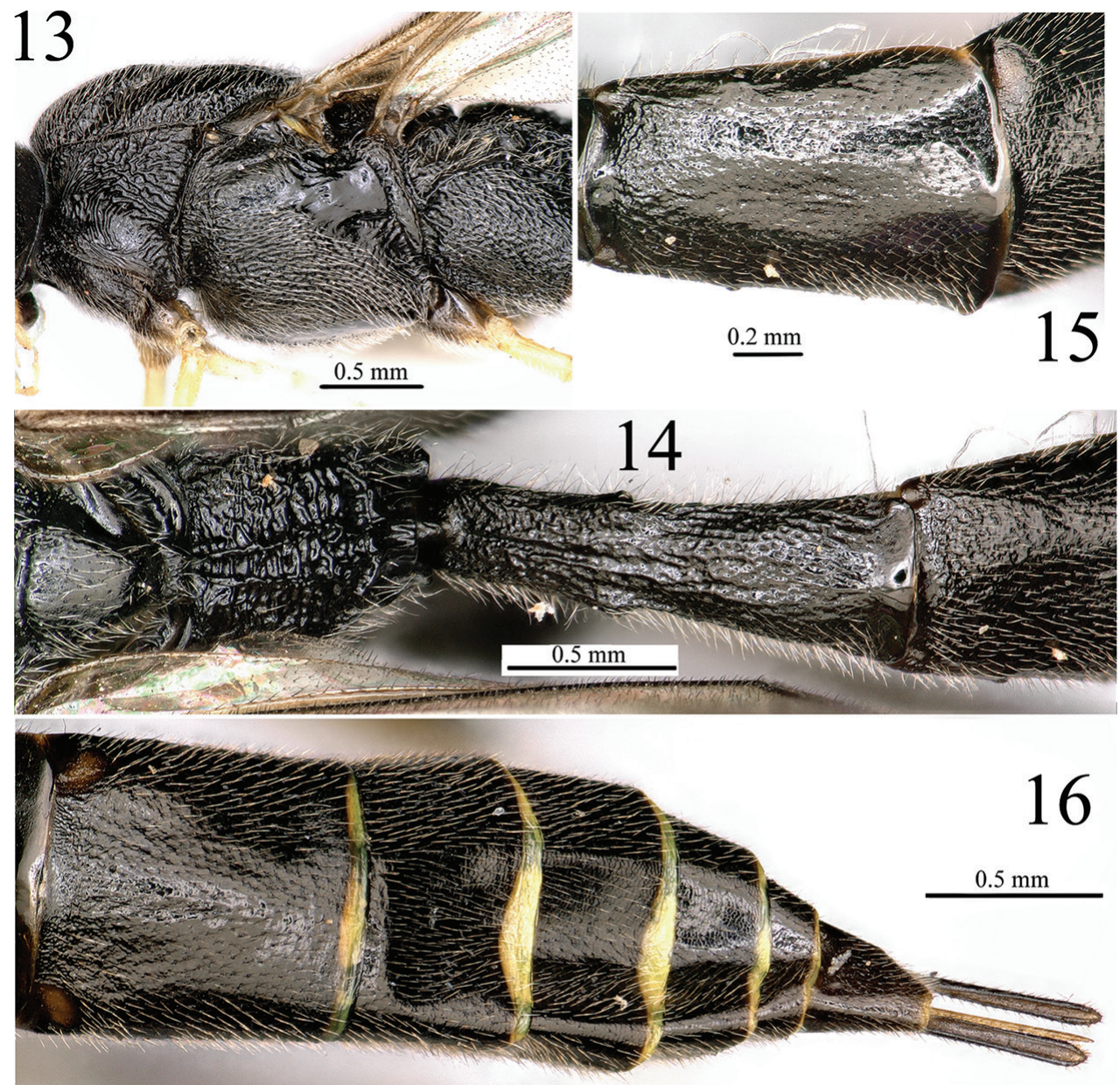

16

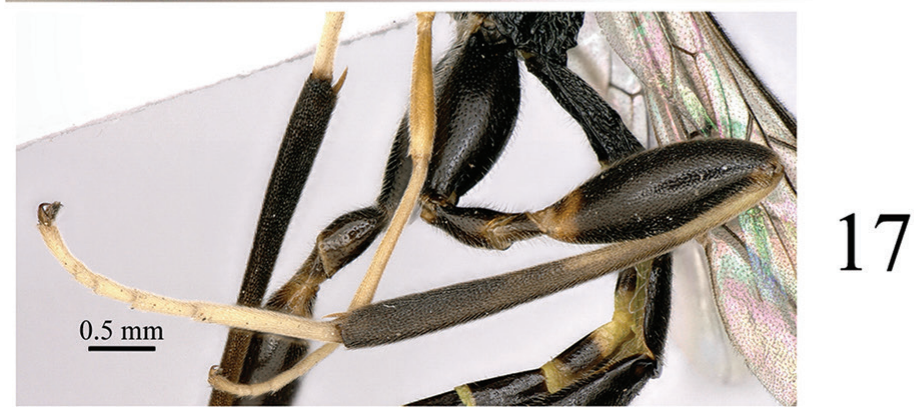

Figures 13-17. Bicurta hejunhuai sp. nov. (female holotype) 13 mesosoma, lateral view I4 scutellum, propodeum, first tergite and base of second tergite, dorsal view $\mathbf{I 5}$ second tergite, dorsolateral view $\mathbf{1 6}$ third to eighth tergites and ovipositor sheath, dorsal view $\mathbf{1 7}$ hind leg lateral view.

wrinkles; pleural carina complete and sharp. Propodeal spiracle elongate, $2.5 \times$ as long as wide, separated from pleural carina by $1.0 \times$ its own longest diameter. 


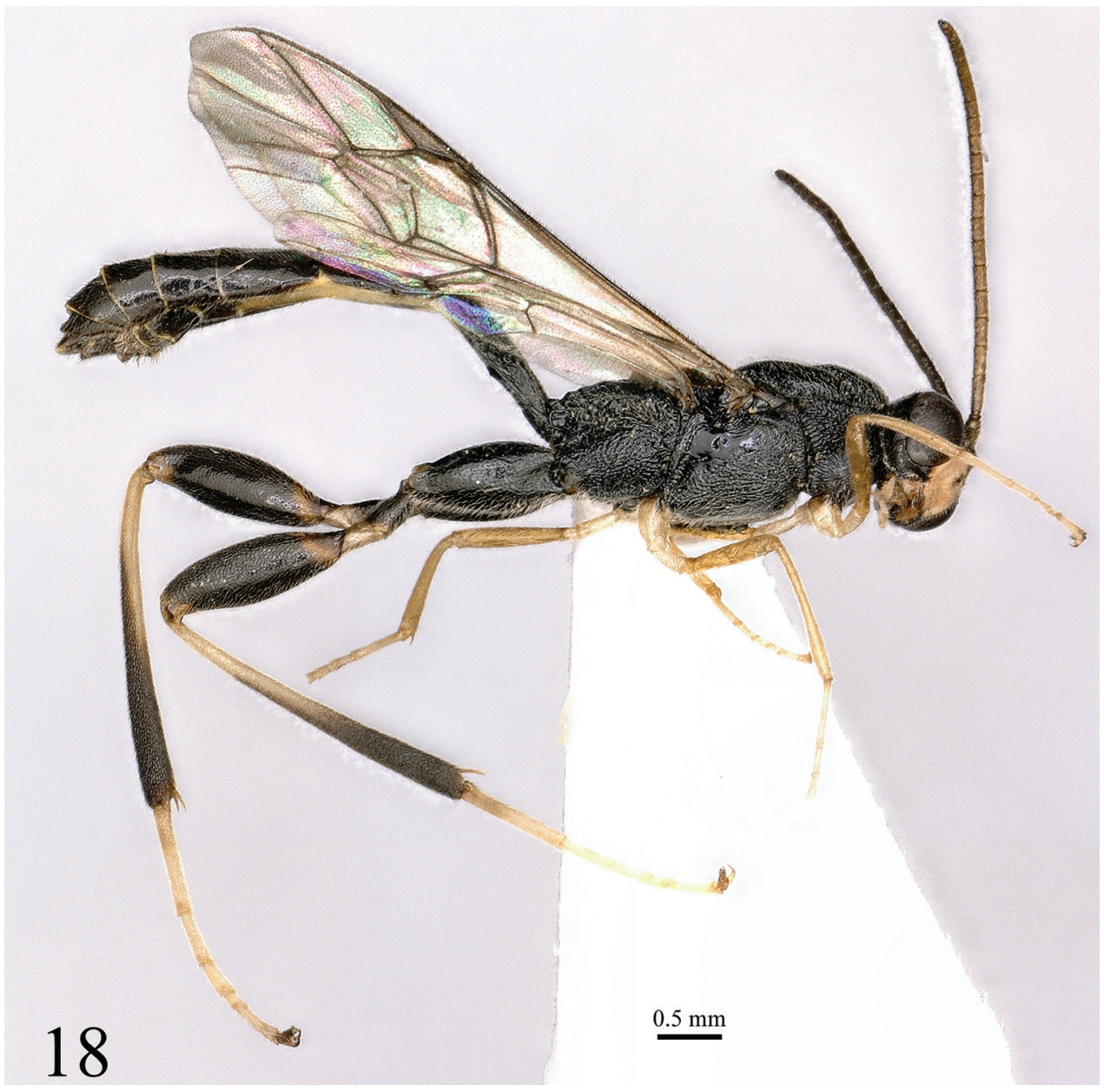

Figure 18. Bicurta hejunhuai sp. nov. (male, paratype) habitus, lateral view.

Wings. Fore wing (Fig. 11) with vein $1 \mathrm{cu}-\mathrm{a}$ distad of M\&RS by $0.2 \times$ length of $1 \mathrm{cu}-\mathrm{a}$; 2 rs-m basad $2 \mathrm{~m}$-cu by $0.83 \times$ length of 2 rs-m. Hind wing with 8 distal hamuli; CU \& cu-a reclivous, distinctly intercepted at upper 0.27 ; distal abscissa of $\mathrm{CU}$ weakly pigmented.

Legs. Fore and mid legs slender. Hind coxa elongate, $3.2 \times$ as long as its maximum width, sparsely punctulate, punctures on dorsal area sparser. Hind femur (Fig. 17) $2.8 \times$ as long as its maximum width. Hind tibia $1.9 \times$ as long as hind femur; tibial spurs very short, inner spur equal to outer spur, $0.18 \times$ length of hind basitarsus. Ratio of length of first to fifth hind tarsomeres as follows: $5: 2.3: 1.5: 1.0: 2.1$. Tarsal claw strongly bent (Fig. 10).

Metasoma. First tergite (Fig. 14) 3.0x as long as its apical width, dorsally rugose punctate, with a longitudinal median furrow on anterior 0.4 , laterally strongly rugose; sclerotized part of first sternite extending behind spiracle, $0.63 \times$ as long as tergite; spiracle convex, located at anterior 0.4. Second tergite (Fig. 15) $1.42 \times$ as long as pos- 

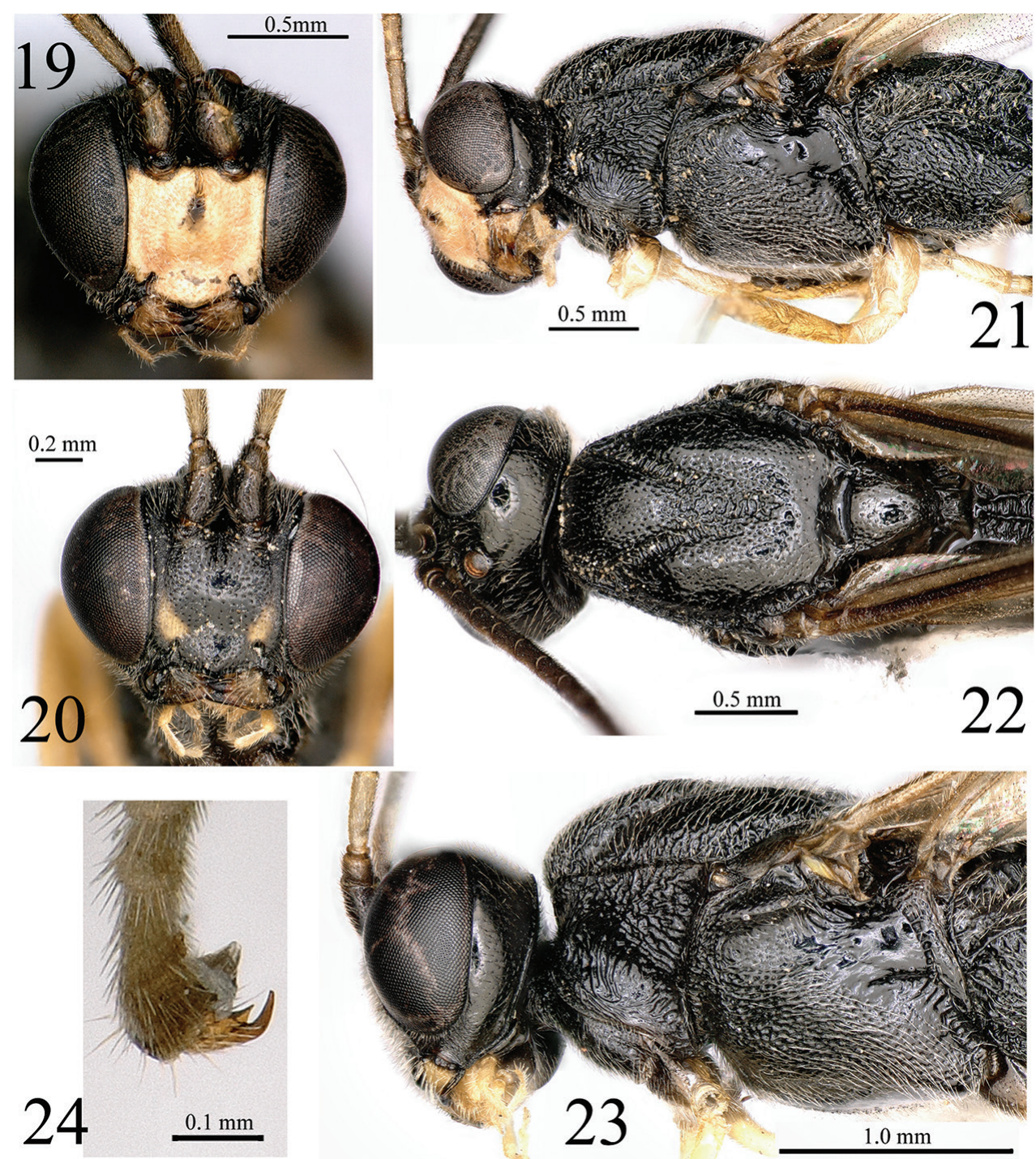

Figures 19-24. Bicurta hejunhuai sp. nov. $\mathbf{9}$ male face, front view $\mathbf{2 0}$ face of female paratype $\mathbf{2} \mathbf{I}$ head and mesosoma of male paratype, lateral view $\mathbf{2 2}$ head and mesosoma of male paratype, dorsal view $\mathbf{2 3}$ head and mesosoma of female type, lateral veiw $\mathbf{2 4}$ mid claw of female paratype.

terior width, anterior 0.2 of tergite granulate punctate, remainder with fine punctures. Third tergite (Fig. 16) finely punctulate, anteriorly with fine leathery texture, anterior lateral corner with a small thyridium on each side. Ovipositor sheath (Fig. 12) 0.25x as long as hind tibia.

Colour. Body mainly black. Head black, face with a pair of obscure yellow marks laterally just above tentorial pits; these yellow marks are very distinct in female paratypes (Fig. 20) and hardly discernible in holotype (Fig. 2). Mandible testaceous with 


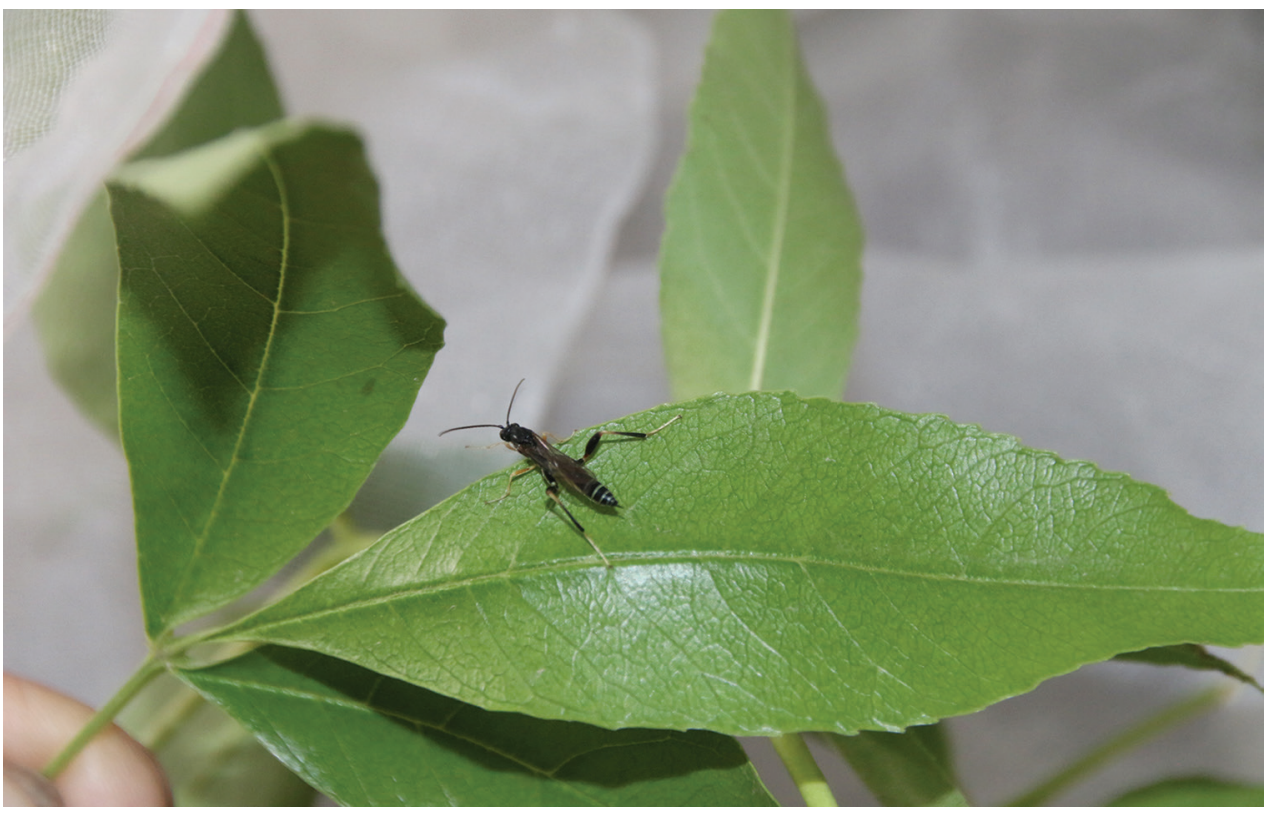

Figure 25. Bicurta hejunhuai sp. nov., female paratype on a leaf of Fraxinus pennsylvanica in Shenyang City, Liaoning province (cell phone photo by Jia-He Yan).

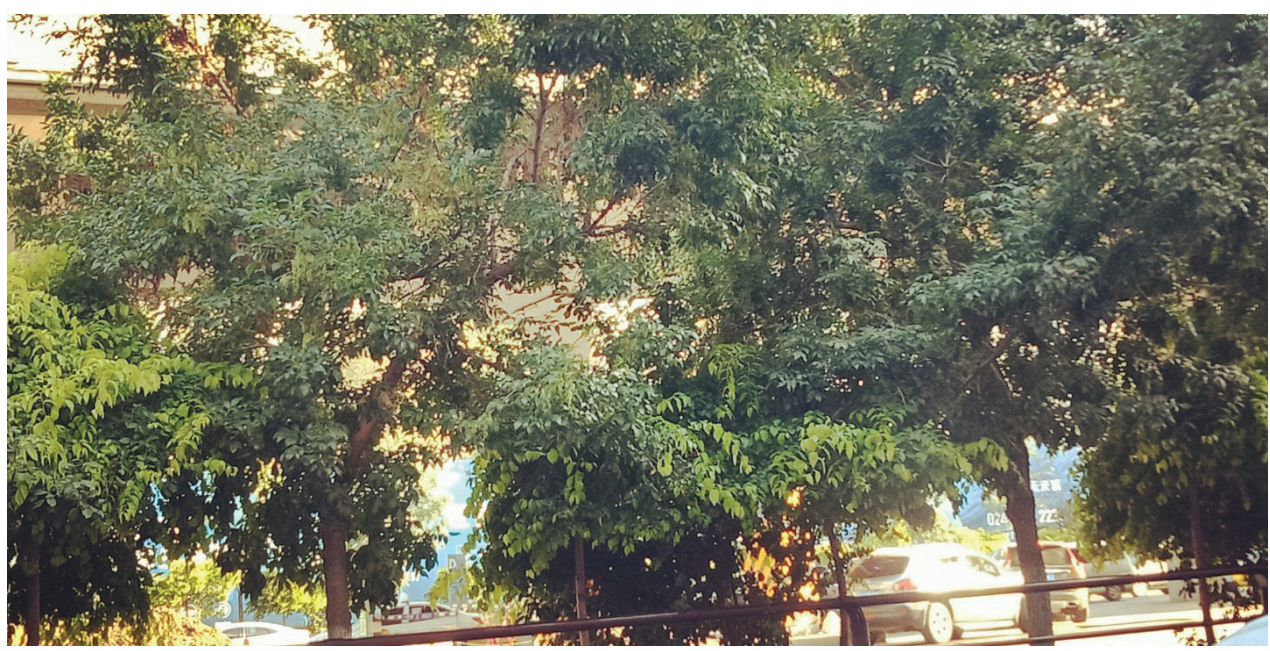

Figure 26. One habitat of Bicurta hejunhuai sp. nov.: greening trees Fraxinus pennsylvanica in the street of Downtown Shenyang City, Liaoning province, China (cell phone photo by Jia-He Yan).

lower margin and apical teeth black. Stipes and prementum black. Labial and maxillary palpi yellow. Antenna with scape and pedicel black, flagellum dorsally blackish brown and ventrally yellowish brown. Fore and mid legs buff with coxae black; hind leg black, apex of trochanter yellow, trochantellus blackish brown, proximal base of hind femur ventrally buff, proximal half of hind tibia ventrally dull yellow and dorsally dark brown to blackish brown, apical half of hind tibia black. Hind margins of 
tergites 1-7 narrowly yellow. Tegula black. Wings hyaline, with veins and pterostigma blackish brown.

Variation. Body length 7.0-10.0 mm. Antenna with 19-20 flagellomeres; yellow spots on face obscure to distinct (Fig. 2, 20).

Male (Fig. 18, 19, 21, 22). Body length $8.2 \mathrm{~mm}$, fore wing $5.4 \mathrm{~mm}$. similar to female. Differences from female as follows: antenna ventrally yellow to yellowish brown; face and clypeus (except lower margin blackish) yellow (Fig. 19), sometimes with a small blackish spot on face centrally; frons with several transverse wrinkles just above antennal sockets; first tergite centrally with two distinct carinae which extend to posterior 0.7 of tergite, posterior tips of carinae irregularly branched. Paramere apically truncate.

Variation. Body length $6.2-8.2 \mathrm{~mm}$, fore wing length $4.6-5.2 \mathrm{~mm}$. Fore wing with vein 1cu-a opposite or slightly distad to M\&RS.

Etymology. The new specie is named in honour of Prof. He Junhua from Zhejiang University in recognition of his years of dedicated and conscientious performance in the study of Chinese Hymenoptera, and also for the celebration of his $90^{\text {th }}$ birthday.

Comparison. The new species is similar to the genotype, $B$. sinica, in its overall appearance and colour pattern. But it can be distinguished from $B$. sinica by the face having two obscure or distinct yellow marks (the face of B. sinica has the ventral inner orbits, clypeus and a stripe passing through the anterior tentorial pits yellow); the mandible weakly narrowed from middle toward the apex, with middle width of mandible $0.57 \times$ as wide as the basal width of mandible ( $B$. sinica with the mandible strongly narrowed from middle toward the apex, with middle width of mandible $0.26 \times$ as wide as the basal width of mandible, measurements based on the figure of Sheng et al. (2012); the central part of the face with sparse punctures (with dense punctures in $B$. sinica); the mesosternum polished, with sparse punctures ( $B$. sinica has the mesosternum densely punctate); and the fore wing vein 1cu-a usually distinctly distad of M\&RS (1cu-a opposite M\&RS in B. sinica).

Biology. The species was reared from the larvae of Stenocephus fraxini Wei (Hymenoptera, Cephidae) in Northern China.

\section{Discussion}

Knowledge of the biology of the subfamily Collyriinae has been limited to life history studies of just two species of Collyria (Salt, 1931; Wahl et al. 2007). Both Collyria coxator (Villers) and C. catoptron Wahl have been shown to be koinobiont endoparasitoids of Cephus (Hymenoptera: Cephidae), ovipositing in the host egg and emerging from the cocooned larva. Sheng et al. (2012) presented detailed morphological evidence that placed the genus Bicurta in the subfamily Collyriinae, despite the very different morphology of the ovipositor. Confirmation that B. hejenhuai sp. nov. is also a parasitoid of larval Cephidae, but in a different habitat (tree twigs as opposed to grass stems) suggests that all collyriines may be koinobiont endoparasitoids of larval cephid sawflies, including the poorly known Aubertiella nigricator (Aubert), which has never been reared. The fine ovipositor of Bicurta species suggests that oviposition will be into host eggs or early instar larvae, although this has not been confirmed. 


\section{Acknowledgements}

We are grateful to Prof. Ming-Yi Tian (SCAU) for his kind help in accessing the digital camera system. This research was supported by the National Basic Research Program of China (No. 2013CB127600) (Jing-Xian Liu) and Basic Research Program of Shandong Province (2017GNC11102) (Jia-He Yan).

\section{Reference}

Broad GR, Shaw MR, Fitton MG (2018) Ichneumonid Wasps (Hymenoptera: Ichneumonidae): Their Classification and Biology. Handbooks for the Identification of British Insects (Vol. 7), part 12, 418 pp.

Gürbüz MF, Kolarov J (2006) A review of the Collyriinae (Hymenoptera: Ichneumonidae). Entomologica Fennica 17: 118-122. https://doi.org/10.33338/ef.84297

Izquierdo IM, Rey del Castillo C (1985) Sobre las especies de Collyria Schiödte, 1839 (Hym., Ichneumonidae). Eos 60(1984): 55-65.

Kuslitzky VS, Kasparyan DR (2011) A new genus of ichneumonid flies of the subfamily Collyriinae (Hymenoptera: Ichneumonidae) from Syria and Israel. Zoosystematica Rossica 20(2):319-324.

Salt G (1931) Parasites of the wheat-stem sawfly, Cephuspygmaeus, Linnaeus, in England. Bulletin of Entomological Research 22: 479-545. https://doi.org/10.1017/S0007485300035355

Sheng ML, Broad GR, Sun SP (2012) A new genus and species of Collyriinae (Hymenoptera, Ichneumonidae). Journal of Hymenoptera Research 25: 103-125. https://doi. org/10.3897/jhr.25.2319

Sheng ML, Sun SP, Ding DS, Luo JG (2013) Ichneumonid Fauna of Jiangxi (Hymenoptera: Ichneumonidae). Beijing: Science Press, 570 pp.

Shang J, Chen TL, Sheng ML (2016) Notes on Bicurta sinicus (Hymenoptera: Ichneumonidae). South China Forestry Science 44(3): 61-62.

Townes HK (1971) The genera of Ichneumonidae, part 4. Memoirs of the American Entomological Institute 17: 1-372.

Wahl DB, Shanower TG, Hoelmer KA (2007) A new species of Collyria Schiødte (Hymenoptera: Ichneumonidae: Collyriinae), a parasitoid of Cephus fumipennis (Hymenoptera: Cephidae) in China, and potential biological control agent for Cephus cinctus in North America. Journal of the Kansas Entomological Society 80(1): 43-50. https://doi. org/10.2317/0022-8567(2007)80[43:ANSOCS]2.0.CO;2

Wei MC, Niu GY, Yan JH (2015) Review of Stenocephus Shinohara (Hymenoptera: Cephidae), with description of a new species from China. Proceedings of the Entomological Society of Washington 117(4): 508-518. https://doi.org/10.4289/0013-8797.117.4.508

Yan JH, Yang QM, Xia MH, Wu WH, Liu HX, Wei MC (2018) Preliminary study on the occurrence and damage of Stenocephus fraxini. Forest Pest and Disease 37(6): 1-5.

Yan JH, Xia MH, Wang XY, Yang QM, Liu HX, Duan CH, Wu WH (2019) Study on the control of Stenocephus fraxini. Shangdong Forestry Science and Technology 2: 30-33.

Yu DS, Achterberg C van, Horstmann K (2016) Taxapad 2016, Ichneumonoidea 2015. Database on flash-drive. Nepean, Ontario. 